\title{
Proverbs in Zhangzhou: Interaction between Language and Culture
}

\author{
Yishan Huang \\ The Australian National University, Australia
}

Doi: 10.19044/llc.v6no2a1

URL:http://dx.doi.org/10.19044/1lc.v6no2a1

\begin{abstract}
This work presents the first attempt to document proverbs of a Southern Min variety of Zhangzhou spoken in Southern China to the audience beyond the Chinese scholarly community. Four different forms of proverbs, namely sayings, allegorical sayings, trisyllabic idioms, and quadrisyllabic idioms, elicited from the field data collected by the author in the urban area of Zhangzhou are described in this study. The various forms differ from each other either in the internal structures, the way the integrated meanings are conveyed, or the number of syllables. Each component of the proverbs is glossed in English and their implied meanings are explained with reference to the associated cultural context of Southern Min. The documentation not only reflects how the local culture is embodied and passed down in terms of speech acts, but also provides valuable evidence for future studies in semantics, pragmatics, and/or anthropological linguistics.
\end{abstract}

Keywords: Saying; allegorical saying; trisyllabic idiom; quadrisyllabic idiom; Zhangzhou.

\section{Introduction:}

Whether called maxims, truisms, idioms, idiomatic expressions, sayings, allusions, and/or adage, proverbs are considered a collection of pithy bits of wisdom and truth that reflect the values and beliefs of a community (Schuster, 1998; Stoch, 2017). They have prevailed for centuries and continue to be used as an effective spoken tool to express various meanings and intentions, ranging from the general truths of advice; values of ambition, virtue, patience, generosity and warning; and summary of human experience; to the instructions that encourage people to act and behave in difficult situations (Mieder, 1993; Schuster, 1998). For example, proverbs like 'when in Rome, do as the Romans do', 'better late than never' and 'big fish eat small fish' are often heard in personal interactions. The proverbs not only have a didactic function to support one's arguments, educate younger generations, or 
enrich daily conversations, but also contribute to the cultures of all nations despite the regional diversities.

The forms of proverbs are diverse. For example, they are understood as Shuyu熟语in Sinitic languages but include saying (Yanyu 浐语), allegorical saying (Xiehouyu歇后语), quadrisyllabic idiom (Chengyu 成语), and other forms of idiomatic expression (Guanyongyu 惯用语). Various forms of proverbs differ from each other with respect to the internal structure $(\mathrm{Li}$, 2016; Ma, 1994; Murar, 2009; Stoch, 2017; Wu, 1995; Yang, 2007). For example, a saying generally involves concise sentence(s). An allegorical saying contains two parts, whereby the first is either a descriptive phrase or a sentence, while the second appears to be an interpretative phrase. Idiomatic expression, instead, is a fixed phrase which functions as a special type of lexeme in full sentences. Thus, it is of linguistic interest to analyse different proverb forms within the formal paradigms of either discourse and/or syntax.

The meanings of proverbs are generally figurative and culturallygrounded (Li, 2016; Murar, 2009). In some circumstances, it appears difficult to deduce the integrated meanings of certain proverbs from their constituents without referencing the associated social-cultural context. In this regard, the insights that a proverb conveys can serve as a window into the history, culture, lifestyle, and mindset of a community being considered (Li, 2016). Learning proverbs of different backgrounds can thus provide a way to expand our multicultural repertoire, and through the sharing of proverbs, we can reinforce the similarities and differences among people around the world (Schuster, 1998).

This paper reports on the first work to document proverbs of a Southern Min variety of Zhangzhou spoken in Southern China to the audience beyond the Chinese community. Four distinct forms-sayings, allegorical sayings, trisyllabic idioms, and quadrisyllabic idioms - are described and interpreted. The chosen examples not only reflect how various forms of proverbs differ in their internal structures and how the local culture is embodied and passed down in terms of speech acts, but also shed light on future studies with respect to semantics, pragmatics, and/or anthropological linguistics.

\section{Zhangzhou and Corpus Zhangzhou}

Zhangzhou 漳州is a prefecture-level city situated in the southern Fujian province in South-eastern Mainland China, at the longitude $116^{\circ} 54^{\prime} 0^{\prime \prime}$ to $118^{\circ} 08^{\prime} 0^{\prime \prime}$ east and latitude $23^{\circ} 34^{\prime} 0^{\prime \prime} \mathrm{N}$ to $25^{\circ} 15^{\prime} 0^{\prime \prime}$ north. It faces the Taiwan Strait to the east and borders Xiamen, Quanzhou, and Longyan to the 
east, northwest, and west, respectively, in Fujian and, to the southwest, Chaozhou in the province of Guangzhou.

According to the Bureau of Statistics (2017) report, the total registered population of Zhangzhou was around 5.10 million, with a natural growth rate of $9.0 \%$. Although the population is ethnically diverse, at about $98.5 \%$, the Han ethnic group predominates, while the remaining $1.5 \%$ or 75,400 inhabitants, most of whom (about 58,000) immigrated to the city either to work or to study, are of 47 nationalities. Zhangzhou has the second largest population of She 畣 ethic group in Fujian and has the largest population of Gaoshan ethic group in Mainland China. Zhangzhou is also well known as the ancestral home of Taiwanese and other overseas Chinese expatriates.

The colloquial language spoken by the majority of inhabitants is Strait Hokkien, which is considered as the ancestor of Southern Min. The southern counties of Dongshan and Zhao'an appear to represent a variety of the adjacent Teochew Southern Min. The two Southern Min varieties have a certain degree of mutual intelligibility, while both are mutually unintelligible in relation to other Sinitic dialects (e.g., Mandarin, Hakka, Cantonese, Wu, Xiang, and Gan).

Mandarin, as the national language of China, is used as a medium of instruction in the educational and public contexts. Hakka is spoken only by a relatively small number of people living in mountainous areas of western Zhangzhou, for example, Hua'an, Nanjing, Pinghe, and Zhao'an counties, bordering a major Hakka-speaking city of Longyan.

\section{Corpus}

Ma (1994) and subsequently Yang (2007) documented the proverbs in this Southern Min variety but in the form of Standard Chinese, constraining their accessibility to those scholars outside the Chinese community. Their phonemic transcriptions, especially in the tonal pitch, are considerably different from those examined in Huang's (2018) study that is grounded in field linguistics and acoustic phonetics. In addition, it appears difficult to identify the source of the data for Ma's work, since the descriptions provided by the author appear not as representative of the urban area as he claimed, but are rather a combination of the sound systems adopted in the urban and other counties, such as Zhangpu.

Thus, the aim of the present study was to provide an accessible and upto-date documentation of this dialect. The corpus presented here was collected in 2015 by the author in conjunction with her field work for her $\mathrm{PhD}$ project. Twenty-one native speakers (nine men and twelve women) from the urban area of Xiangcheng and Longwen districts were recorded for the tone sandhi investigation. In addition, another group of six native speakers (four men and two women) was recorded for local vocabulary documentation. All twenty- 
seven speakers included in the investigation were asked to offer a short narrative, local stories, proverbs or rhyming songs, or contribute other speech that they wished to share. The recordings of proverbs that were mainly provided by male speakers constitute the corpus presented in this study. All informants were born and raised in the inner city and have spoken Zhangzhou Southern Min as their primary colloquial language since childhood. Their parents and spouses are all native speakers as well. This selection of informants ensures that the obtained data is representative of this Southern Min variety.

In the present study, the transcriptions of both segments and suprasegments are kept consistent with those formulated by Huang (2018). Segments were transcribed using IPA 2005 symbols, whereas the tonal pitch was described using Chao's (1930) notational system with 1 representing the lowest level and 5 the highest of the individual's pitch range. For example, a level tone is represented by two instances of the same number (e.g., [33] or [55]), and a rising or falling tone is represented by increasing and decreasing numbers, respectively (e.g., [25] or [51]). When required, 6 was introduced to denote the tone having extra-high pitch level in the non-utterance final context. In what follows, each component of the proverbs is glossed in English before providing explanation of their implied meanings in italics. The details on the research locality and speaker selection, the data collection procedure, as well as the segmental and suprasegmental system of Zhangzhou Southern Min, can be found in Huang's (2018) thesis.

\section{Sayings}

The sayings documented here are understood as Yanyu谙语 in Sinitic culture. They generally involve grammatically full sentence to express an observation, opinion, advice, or a wisdom that exists in a vernacular form and could be memorised easily (Stoch, 2017). The meanings of sayings are not always figurative; instead, they can be explicitly stated. The contents conveyed in sayings are diverse, covering family, education, strength, health, success, and social networking topics, among others.
1. tse63 koj35
tse63 ke63 2em63.bin33.6on35
be grandpa
be until late and dark

'Being a grandpa means being [active] until the day is late and dark.'

$\begin{array}{lllllll}\text { tse63 } & \mathbf{6} \tilde{\mathbf{\varepsilon 5 1}} & \mathbf{t s \theta 6 3} & \mathbf{k e 6 3} & \mathbf{k j \theta 6 3} & \mathbf{2 m 3 2} & \mathbf{k} \tilde{\mathbf{b} 51} \\ \text { be } & \text { grandma } & \text { be } & \text { until } & \text { shout } & \text { Neg. } & \text { dare }\end{array}$

'Being a grandma means being [active] until she does not dare to do so.' 
Grandparents used to look after their grandchildren while the parents did farm work. This saying draws reference to the long days spent by the grandparents at this task.

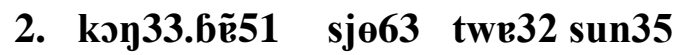

grandparents favour big grandson

'Grandparents like the eldest grandson.'

pe32.6ө51 sje63 se63 kjẽ51

parent favour small kid

'Parents like the youngest kid.'

The idea that grandparents love their eldest grandson for representing the start of a new generation while parents dote on the youngest suggests the differing views that individuals in differing circumstances can have on their surroundings.

3. бrj35 6rj35 $2 \varepsilon \quad \sin 33 . p u 33$ sje35;

bad bad partial daughter-in-law three quantifier cook

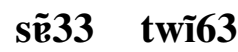

'The daughter-in-law is bad, but she cooks three meals each day.'

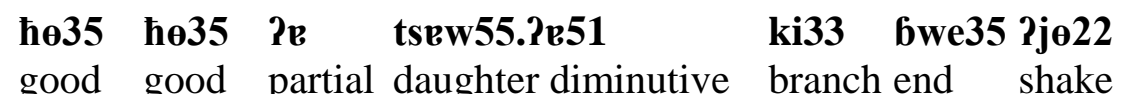

'The daughter is good, but she just likes a swaying branch of a tree.'

In this vision of the past, the daughter-in-law, though not desirable, does crucial housework, while the daughter, though desirable, visits her parents only occasionally.

4. $\operatorname{kin} 55.2 v \quad t s j \tilde{v} 35$

kid dimi. elf

Pu32 hi33 th thĩ $35^{-}$

have ears listen 


$\begin{array}{lllll}\text { Pu32 } & \text { ts }^{\text {h }} \text { wi41 } & \text { bey32 } & \text { tse63 } & \text { sje } 35 \\ \text { have } & \text { mouth } & \text { does not } & \text { make } & \text { sound }\end{array}$

'Elf child, listen with your ears, but keep your mouth closed.'

Parents admonish their children to keep silent and not to speak up when adults are having a discussion. The English equivalent is " $a$ child should be seen and not heard."

\section{5. pwi32 $\sin 22$ hon33.te63 twe33}

meal deity emperor big

'The dinner god is as big as an emperor.'

Having meals is an important part of daily life, so children are admonished to concentrate on eating and not to be distracted during meal times.

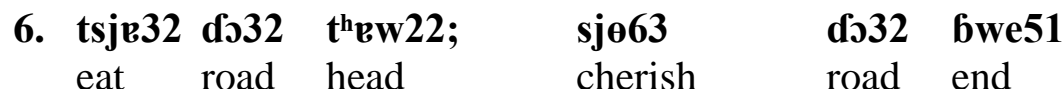

'Relying (on someone's help) at the beginning of a journey; cherishing (him) at the end as well.'

This saying advises cherishing forever the persons/things that were helpful at the beginning.

7. th $^{\mathrm{h}}$ 6363 tsĩ22 be33 so41; earn money no number

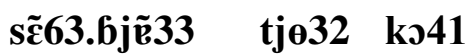

life need take care

'However much you earn, you need to take care of your health.'

This saying admonishes individuals not to lose sight of what is more important - their live/health-while they are earning money.

\section{8. tse63 hi63 thew22; $\mathbf{k}^{\text {hit65.tsje32 }}$ bwe51}

perform dramabegin beggar end

'An actor at the beginning; a beggar in the end.'

The idea here is that someone living a life of luxury, such as an actor, ends up penniless later in life. Thus, elders would admonish the younger generation not to squander the things that they had. The English equivalent is "Here today, gone tomorrow." 


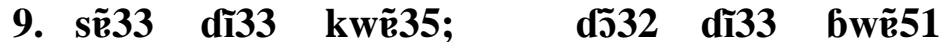 \\ three year official two year full}

'A three-year official has had enough in two.'

The proverbial official has a three-year-long mandate but tires of it well before his tenure is up. The notion is that individuals tend to lose their enthusiasm over time, while also suggesting that some officials are unable to devote themselves fully to serving the public.

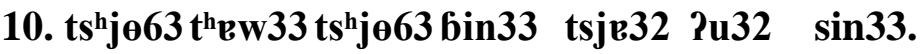
smile head smile face eat have leftover

'A smiling face leaves one with leftovers.'

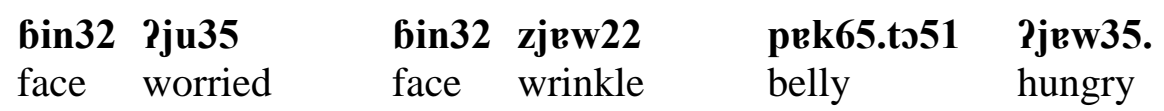

'A worried and wrinkled face leaves one with a hungry belly.'

The notion here is that a positive personality brings one more than enough to eat, while a negative personality brings one bad luck and not enough to eat.

\section{1. tse33.6951 swi35 Gek32.tsju35;}

women beautiful eyes

'Women are beautiful for their eyes.'

$\begin{array}{lll}\text { tse33.po33 } & \text { swi35 } & \text { ts }^{\text {hi63.tsh }} \text { ju35 } \\ \text { man } & \text { beautiful } & \text { beard }\end{array}$

'Men are beautiful for their beards.'

The notion here is that different classes of people are judged differently and that individuals view their surroundings in unique ways. This saying conveys an admonishment to have an open and positive attitude and to accentuate what is positive.

\begin{tabular}{|c|c|}
\hline $\begin{array}{l}\text {. ts }{ }^{\text {he33.be33 }} \\
\text { blind }\end{array}$ & $\begin{array}{l}\text { tsin35; } \\
\text { precise }\end{array}$ \\
\hline
\end{tabular}


'Though blind, the blind man is precise; though dumb, the dumb man is nimble.'

The disabled compensate for their disabilities; more broadly, individuals tend to have defects but also merits.

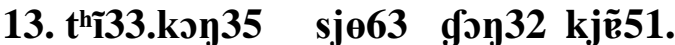

heaven deity favour stupid kid

'The deity of heaven favours stupid kids.'

Even foolish people can prosper.

\section{4. twe32 pun51 pwe32 be33 dun51}

big capital gamblenot fear

'There is no fear of gambling when one has lots of money.'

This saying expresses the idea that the possession of resources brings confidence and also that officials sometimes squander public funds on themselves.

\section{2s33.ku35 kẽ 35 twe32.?jв22;}

turtle fake big man

'A turtle is a fake big man.'

$k^{h}$ it65.tsje22 $\quad k \tilde{\varepsilon} 35$ de35.tjø35

beggar fake offical

'A beggar is a fake official.'

The notion here is that those without power may behave in an overbearing manner as if they are powerful.

16. $k^{\text {hi35 }}$ ts $^{\mathrm{h}} \mathrm{u} 41 \mathrm{p}^{\mathrm{h}}$ ej63 build house dispatch

\section{pwẽ63 djew33}

half material

'Offer half the material to build a house.'

This saying describes a negative social phenomenon: some individuals do shoddy work, skimping on the materials and thus their commitments to others. 
17. zin33 tsin22

human relation

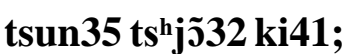

just like saw

\section{Pu32 dej22 kө63 Pu32 $\mathbf{k}^{\text {hi41 }}$ \\ have come also have go}

'Relationships among people are like a saw going back and forth.'

Maintaining a relationship between individuals requires effort from both.

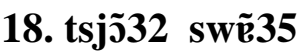

$\mathbf{k}^{\mathrm{h}} \mathbf{w} \tilde{\mathbf{E}} 63$

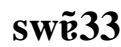

si41;

climb mountain

observe

mountain

shape

'Climb a mount in to observe its shape.'

zip32 6wĩ22 $\mathbf{k}^{\mathrm{h}} \mathbf{w} \mathbf{\varepsilon} 63$

deg33 Pi41.

enter door observe

people feeling

'When you to in, observe the host's feelings.'

Here the idea is that one should maintain a flexible attitude and adjust to changing surroundings.

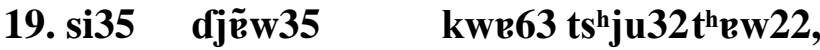

dead cat hang tree head

'Hang a dead cat on a tree.'

$\begin{array}{lll}\text { si35 } & \text { kew51 } & \text { pen63 tswi35 dew22. } \\ \text { dead } & \operatorname{dog} & \text { place water flow }\end{array}$

'Let a dead dog be washed away.'

This saying suggests that each individual has his or her own destination and that different issues have different solutions. It also advises remaining flexible and open to the world.

20. $\operatorname{ts}$ in 33

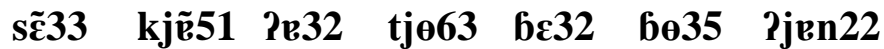

blood-related birth kid also need father mother destiny

'Kids also need a predestined relationship with their parents.' 
This saying suggests that parents have a large influence on their children's lives and that individuals should be tolerant of the unfairness that they may encounter in life. It also reflects a general faith in Sinitic culture.

\section{1. tse33.6o35}

female

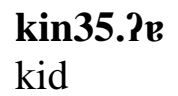

tshej63

vegetable

\section{tsi35 6jë33}

seed destiny

'Girls have a destiny like that of vegetable seeds.'

This saying reflects the limited control that women used to have over their lives in the old days, since they left their parents after marriage, like seeds that scatter and grow wherever they end up.

22. ts ${ }^{\mathrm{h}} \mathbf{p j} 32$ to35 Pm32 dej33; dej32 tsjen33

si22 vegetable knife Neg. sharp sharp fry spatula

'A blunt kitchen knife but a sharp frying spatula.'

This saying inverts the usual situation, in which the knife is expected to be sharper than the spatula; the implication is that, also contrary to expectations, men do not perform better than women.

23. $p^{\mathrm{h}} \mathrm{e63}$ ho51

$$
\text { dje32 ts } \text { tst221 }^{\mathrm{h}}
$$

ts ${ }^{\text {hin }}$

hjể33.ti33

beat tiger catch thief

blood-related brother

'Blood brothers overcome the tiger and catch the thief together.'

The idea here is that close relations work together at crucial moments to confront threats, meaning that family members are the most supportive individuals in one's life and need to be cherished.

\section{6ө33 hө35 si32.twe33; de32 bө33 hө35 si32.se41.} no good adults then no good children

'No-good parents mean no-good children.'

This saying suggests that parents need to be a good role models for the next generation. The English equivalent is "The apple doesn't fall far from the tree."

25. sjew63

young

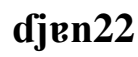

year 2m32 p $^{\mathrm{h}} \mathbf{6 6 3 . p j} \tilde{\mathbf{r}} \mathbf{4 1}$

Neg. strive 
'No striving in youth.'

\section{tsje32 dew33 bө33 bjẽ 33.sjẽ 35 \\ eat old Neg. reputation}

'No reputation in old age.'

This saying suggests that success in life depends on hard work early on.

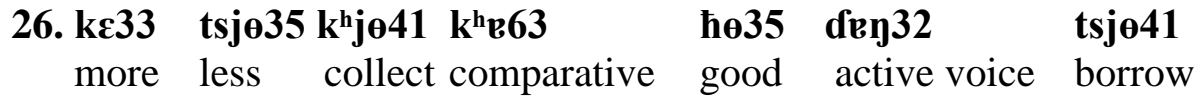

'Gathering is better than borrowing.'

This saying encourages self-sufficiency, indicating that accumulating a modest amount of resources is better than borrowing from others.

\section{7. tsit32 hө32 bi51 tsje32 pe63 Pjj332 den22.}

one size rice eat hundred type people

'One type of rice can nourish a hundred kinds of people.'

This saying suggests that those who are raised in the same background can have different personalities, for better or worse.

\section{2ju33.kem35 he35 bwe35 bi33;}

gooseberry good final flavor

'The gooseberry is sweet in the end.'

\section{Køm33.tsjø41 thew33 bwe35 tĩ35.}

sugarcane head end sweet

'The sugar cane is sweet from one end to the other.'

The idea here is that some experiences are pleasurable all the way through and others only at the end, suggesting that even those whose lives begin in difficulty may find sweetness in old age

\section{Allegorical Sayings}

Allegorical sayings, known as Xiehouyu 歇后语in Sinitic languages, as one kind of proverbs, are unique in terms of form (Lai, 2008). They contain two parts: one portraying an image of an object, an event, or a situation, and 
the other indicating the meaning to be derived from the first part. The first part can be either a phrase or a cause that functions as a subject; while the second part appears to be a predictive phrase. Their combination forms a full sentence that conveys information to be derived through conceptual mechanisms. In this section, nine allegorical sayings are presented, all of which are rooted in the folk knowledge with a high degree of colloquialism and reflect general opinions of Zhangzhou community. The two constituent parts mentioned above are separated by an em-dash.

1. $p^{\text {he63.tsi22 }}$ ts $^{\text {hju }}$ 35kut41

beat break hand bone

- to63 2joj51

instead strong

'A fractured hand is that much stronger.'

The idea here is that hardship makes an individual stronger.

2. tshit65 Pe pwĩ63 Pr55.2v

seven Poss. half duck

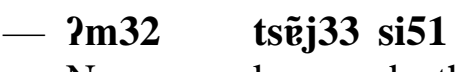

Neg. know death

'Ducks on the mid-July don't foresee their deaths.'

In Southern Min culture, thanksgiving offerings, mainly cooked poultry, including duck, are presented to deceased family members in the middle of the seventh month of the Chinese calendar (corresponding to mid-July), something of which the ducks are of course unaware. The idea is that individuals are often unprepared for momentous events in their lives.

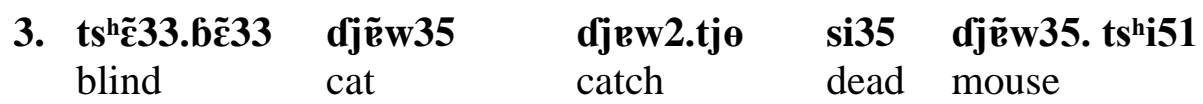

\section{- thew63.tu35.k $^{\text {h}}$ em51}

as luck would have it

'A blind cat catches a dead mouse.'

Since a blind cat would be a poor hunter of mice, its luck in coming across a dead mouse suggests the possibility of a happy coincidence. 


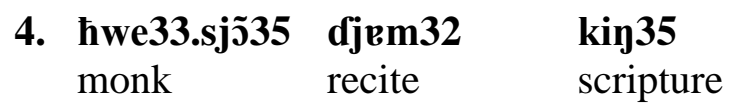

$\begin{array}{llll}- \text { Pu32 } & \text { ts }^{\mathrm{h}} \mathbf{w i 4 1} & \text { be33 } & \operatorname{sim} 35\end{array}$

have mouth no heart

'A monk recites the scripture with his mouth but not in his heart.'

This saying describes an individual who is merely going through the motions when performing an important task.

5. ts ${ }^{\mathrm{h}} \mathrm{ew35.d \tilde { \varepsilon } 4 1}$ den32 ke33 kвฤ35

grasshopper tease chicken male

- ts ${ }^{\mathrm{h}} \mathrm{we} 32$ si41

seek death

'The grasshopper teases the rooster to its peril.'

This saying describes individuals who take risks foolishly or in ignorance,

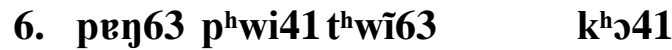

release fart take off trouser

- ke33 kej35 add effort

'He takes his pants off to fart.'

This saying describes an individual prone to taking unnecessary actions.

7. 6ө33 ki51 tsje32 tew32 hu33

no tooth eat bean curd

$\begin{array}{cl}\text { tu35 } & \text { hө51 } \\ \text { just } & \text { fine }\end{array}$

'The toothless man has no problem eating bean curd.'

This saying describes how individuals find ways to meet their needs despite obstacles. 


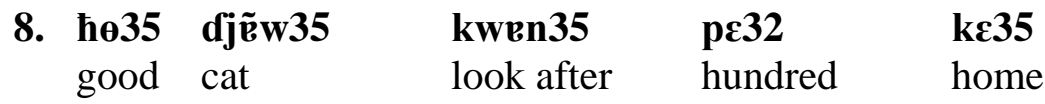

- ke33 pe22

home old lady

'A good cat looks after hundred homes.'

In Southern Min culture, old women are often regarded as involving themselves in affairs that are and are not their concern, so the saying criticizes meddlesome individuals.

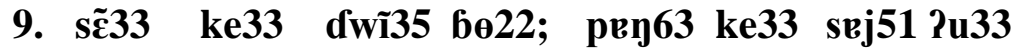

bear hen egg no place hen shit yes

\section{—6ө33.dð32.2joy33}

useless

'When a hen bears an egg, don't keep it in chicken shit.'

This saying describes an unproductive action.

\section{Trisyllabic Idioms}

Trisyllabic idioms are referred to as conventionalised expression (Guanyongyu 惯用语) in Sinitic languages. They differ from sayings and allegorical sayings in terms of the internal structure, while differing from other forms of idiomatic expressions in the number of syllables and/or the source/origin. The trisyllabic idioms are colloquialisms that are created and formed by the community members in the course of their everyday activities. They are mostly used to express emotional attitudes, such as disappointment, disgust, or appreciation. They function as a single lexeme in full sentences, but differ from other common lexemes by virtue of their conventional implications, which is difficult to deduce based on the literary meanings of individual components. Below, 18 trisyllabic idioms that are commonly heard in the local society are introduced.

\section{6ө33 6rk32.tsju35}

no eye

'Eyeless.'

This term describes individuals who are indifferent to the world around them. 


\section{6ө33 ts ${ }^{\mathrm{h}} \mathrm{ej} 35 . \mathrm{ke \eta} 35$}

no effort

'No effort.'

This saying describes an individual who wastes effort on something unworthy.

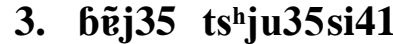

bad hand posture

'Bad gesture'

This saying describes an individual who is unlucky at gambling.

4. gð32 ki33 ts ${ }^{\text {hju35 }}$

five quantifier beard

'Five beards.'

This saying describes a lustful man, known as a 'cat' in Southern Min culture.

5. kĩ63 tsĩ33 si51

see money death

'Die of seeing money.'

This saying describes an individual who places financial gain above all else.

6. 2jew35

sju32

shorten po33

strategy

'A fatal strategy.'

This saying describes an unworkable strategy.

\section{7. $2033 \quad$ 2e33 ts ${ }^{\mathrm{h}}$ wi41}

black crow mouth

'With a crow's black mouth.'

This saying describes an individual who says something undesirable and ominous; the crow represents bad luck in Sinitic culture. 
8. tek65 ts ${ }^{\text {h }}$ wi63 $\quad k 551$

fight mouth drum

'Bicker.'

This saying describes individuals who are joking around.

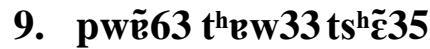

half head immature

'With a head half-grown.'

This saying describes an individual whose actions and decisions show a lack of maturity.

\section{0. ?m32 kew63 kwi51}

Neg. enoughghost

'Not enough of a ghost.'

This saying describes an individual who acts or dresses in an inappropriate manner.

11. hө35 ts ${ }^{\text {hwi63 }}$ tswi51

good mouth status

'He keeps his mouth good.'

This saying describes an individual who likes to greet others with soothing words.

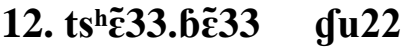

blind cow

'A blind cow.'

This saying describes an illiterate individual suited only to menial labour.

\section{3. kew32 ?we32 sej51}

thick speech shit

'Diarrhoea mouth.'

This saying describes an individual who is overly talkative. 
14. $\operatorname{sen} 63$

ke63

2m41

send

marriage aunt

'An aunt of the bride duties.'

This saying describes an individual is knowledgeable about the surrounding culture and also likes to dictate orders. In Southern Min culture, this term also refers to a professional (usually female) who provides services relating to traditional weddings.

15. k\&33

pe33

home elder woman

se51

sister-in-law

'The old sister-in-law in the house.'

This saying describes a woman who likes to involve herself in the affairs of others. Traditionally, women stayed at home to do housework and, when they met together, were thought to gossip.

16. $\mathrm{t}^{\mathrm{h}}$ $\mathrm{ew} 33$ tsje32

steal eat

po33

step

'Gain sth. by trickery'

This saying describes individuals who take advantage of the rules to further their own purposes.

17. $\mathrm{k}^{\mathrm{h}} \mathrm{jew63}$

bend upwards

\section{ts ${ }^{\text {hwi63.tswi51 }}$}

mouth lips

'Purse up one's lips.'

This saying describes an individual who is unhappy with an outcome or decision.

\section{8. dew63 ?E32 hem35}

drop lower jaw

'He's dropping his jaw.'

This saying describes an individual who is overstating something. 


\section{Quadrisyllabic Idioms}

Quadrisyllabic idioms known as chengyu 成语in Sinitic culture are distinguished by form and function from sayings and allegorical sayings, while being distinct from trisyllabic idioms in terms of the number of syllables and sources. The quadrisyllabic idioms of Zhangzhou are largely colloquial, and their meanings appear deducible from their constituents. They are full of rhythm and cadence that can be divided into two feet, a tempo that is easy to verbalise and memorise ( $\mathrm{Wu}, 1995)$. Due to their colloquial and rhythmic features, the quadrisyllabic idioms are commonly used by native speakers in everyday conversations to congratulate, attract attention, advise, suggest, or to warn. In this section, 18 quadrisyllabic idioms are presented to reflect the interaction between Southern Min language and culture.

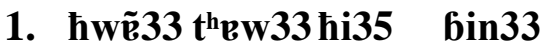

happy head happy face

'Happy thoughts, happy face.'

This saying suggests that happiness is an honest emotion.

2. tsjem33

needle

\section{$k^{\text {he33 }}$ 2ju63 ts ts ju51 $^{\text {he }}$}

foot tender hand

'With a needle foot and a tender hand.'

This phrase describes an individual who is pampered.

3. $\mathbf{t}^{\mathrm{h}}$ ij33 ke35

kill chicken

\section{ke63 kew22}

teach monkey

'Kill the chicken to teach the monkey.'

This saying describes punishing one individual as a warning to others.

\section{4. dun35}

\section{$k^{\text {hi41 }}$ kju33 tsvj22}

tolerate

$$
\text { breath pursuit wealth }
$$

'Put up with [bad] breath to pursue wealth.'

This statement suggests that one should not lose out on business opportunities because of another's unpleasant personal characteristics.

\section{5. di33 sjë35 be35 hew51}

donkeyvoice horse cry 
'The voice of a donkey and the braying of a horse.'

This saying is used to describe harsh voices or songs.

\section{6. pr35 dí33 pr33 tse41}

full year full festival

'Full year, full festival.'

This saying describes abundance at new year's festivals.

7. $k^{\mathrm{h}}$ ๒ฺ33 ts ${ }^{\mathrm{h}}$ wi63

po32 tsi22

empty mouth

chew tongue

'Empty your mouth and chew your tongue.'

This saying is used to describe individuals who gossip and say foolish things.

8. 2o33 ku35 pi63 tswe22

black turtle tortoisesnake

'Black turtles, tortoises, and snakes.'

This saying is used to describe a group of undesirable individuals.

\section{9. dwĩ35 th th22 $^{\text {h }}$ tsim33 $^{\text {him }}$ kut221}

soft soil deep dig

'Dig deep in soft soil.'

This saying describes individuals who are easily bullied.

10. dẹ33 dej33 ke63 ki41

people come guest go

'People come, guests go.'

This saying emphasizes the importance of mutual interactions for maintaining a relationship.

11. ts ${ }^{\text {hew63 }} \quad t^{\text {thew22 }}$ kew32 2 je22

stinking head thick medicine

'Stinking head, thick medicine.' 
This saying indicates that individuals with a certain disease encounter a series of troubles.

\section{2. dje32 ku35 tsew35pi41}

catch turtle escape tortoise

'Catch one turtle, lose tortoise.'

This saying describes individuals who lose one thing while attending to another.

13. sem33 put65 go32 si22

three unlike five hour

'More like three than five hours.'

This saying is used to describe something that happens very frequently.

\section{6ө33 gu22 srj35 be51}

no cow use horse

'If there's no cow, use a horse.'

This saying describes the need to adjust to the changing circumstances.

\section{5. put65 sem35 su32 djen51}

unlike three like two

'More like two than three.'

This saying is used to refer to things or people that appear strange and are difficult to classify, are 'neither fish nor fowl.'

16. pi35 tshju35

gesturehand
Pwr32 to35

draw knife

'Use hands to draw a knife.'

This saying describes an individual who likes to use body language and also indicates that some individuals like to involve themselves in others' business. 


\section{7. ?u32 2jen22 be33 ts ton $22^{\text {he }}$}

have fate no decline

'Don't decline a person who has a predestined relationship.'

To express that people emphasize a predestined relationship in their social activities.

18. ts h $^{\mathbf{\varepsilon}} 33$

th $^{\text {h }} \mathbf{w} 33$ ts ts $^{\text {h }} 33$

immature head immature bin33

face

'Youthful face, youthful mind.'

This saying describes an individual who is indifferent and arrogant.

\section{References:}

1. Chao, Y. (1930). ə sistəm əv "toun-lktəz" (A system of "tone letters"). Le Maître Phonétique, 45, 24-27.

2. Huang, Y. (2018). Tones in Zhangzhou: Pitch and beyond ( $\mathrm{PhD}$ dissertation: Australian National University). Retrieved from https://openresearch-repository.anu.edu.au/handle/1885/144938

3. Lai, H.-1. (2008). Understanding and classifying two-part allegorical sayings: Metonymy, metaphor, and cultural constraints. Journal of Pragmatics, 40, 454-474.

4. Li, Y. (2016). Comparison of the comprehension of three types of Chinese colloquial idioms by advanced Chinese L2 learners. ( $\mathrm{PhD}$ dissertation: The University of Iowa). Retrieved from https://ir.uiowa.edu/etd/2112/

5. Ma, C. (1994). Studies of Zhangzhou dialect (Zhangzhou Fangyan Yanjiu). Hongkong: Zongheng Publishing House.

6. Murar, I. (2009). Pragmatic and functional uses of idioms. Analele Universității din Craiova. Seria Științe Filologice. Lingvistică, XXXI, $1-2$

7. Schuster, \& Ellen. (1998). Proverbs: A Path to understanding different cultures. Journal of Extension, 36(1). Retrieved from https://www.joe.org/joe/1998february/tt2.php

8. Stoch, N. (2017). Distinctive Features of Chinese proverbs: A comparative study of suyu and yanyu and other types of shuyu. Annals of Arts, 64(9), 47-68.

9. Wu, C. H. (1995). On the cultural traits of Chinese idioms. Intercultural Communication Studies, 5, 61-82. 
10. Yang, X. (2007). Proverbs and songs in Zhangzhou dialect (Zhangzhou Fangyan Shuyu Geyao). Fuzhou, China: Fujian People's Publishing House. 